\title{
"O humor mostra... como as coisas não devem ser": uma entrevista com Ciça
}

\author{
"Humor shows... how things shouldn't be": an interview with Ciça \\ Cintia Lima Crescêncio' \\ 0000-0002-2992-9417 \\ 'Universidade Federal do Mato Grosso do Sul, Departamento de História, Três Lagoas, \\ MS, Brasil. 79600-080 - reitoria@ufms.br
}

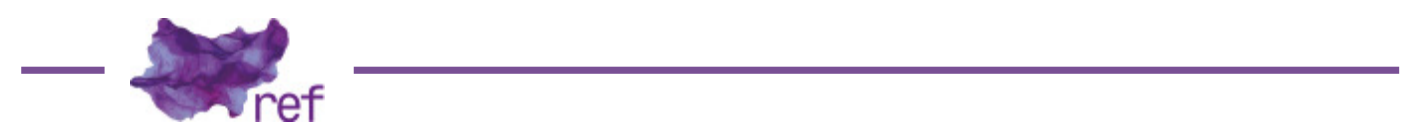

Atualmente o universo dos quadrinhos e do humor gráfico tem se mostrado campo de interesse das mulheres que, por muito tempo, foram desprezadas por grandes editoras e jornais, ou mesmo silenciadas por enciclopédias e genealogias que contam a história dos quadrinhos e do humor gráfico brasileiros. A Internet, hoje, tem papel importante e afirma-se como veículo de quadrinistas e cartunistas mulheres independentes. Há algumas décadas, no entanto, o cenário era mais hostil e, apesar dos esforços de recuperação das histórias de mulheres cartunistas e quadrinistas, sabemos pouco sobre elas. Nesse sentido, a entrevista com Ciça, que compõe esta seção, é um movimento em direção à construção das histórias de mulheres, histórias feministas, que marcaram a história do humor gráfico brasileiro. Cecília Alves Pinto, mais conhecida como Ciça, cartunista e criadora de personagens como O Pato e Bia Sabiá, publicou em jornais como $O$ Pasquim, Folha de S. Paulo, Brasil Mulher, Nós Mulheres e Mulherio e é um dos principais nomes do humor gráfico nacional. Em 2019, num ato de justiça, o Troféu Angelo Agostini, através de votação popular, a elegeu como um dos mestres (no masculino) do quadrinho nacional. Em 11 de abril de 2017, durante uma ensolarada tarde paulistana, Ciça concedeu essa entrevista que integra um projeto político e histórico de contar histórias de mulheres cartunistas que, antes da Internet, exploraram o humor e a arte como ferramenta de mudança.

Entrevistadora (CLC): Como foi seu contato com a arte?

Ciça (C): Durante minha adolescência no Rio de Janeiro, fui para lá com 13 anos. Meus tios trabalhavam na revista Cruzeiro e meu tio era diretor do semanário. A casa dele era um polo e nós morávamos no mesmo prédio. Eu tive convivência com figuras da música, da literatura, do jornalismo e da política. Tive contato com a arte desde muito cedo. E com política também. Eles iam lá para confabular. Isso por volta dos anos 1950, no final de 1950. Meu avô foi ministro da Fazenda do presidente Café Filho. Eu gostava disso... gostava de política o suficiente para fazer política estudantil, não me metia lá na União Nacional dos Estudantes (UNE) que era de estudantes formados, de universidade, mas tinha a União Nacional dos Estudantes Secundaristas (UBES) e eu estava lá, eu gostava. Junto desse pessoal de arte eu fiquei muito amiga do Millôr Fernandes, do Ziraldo, dessa turma que fazia humor, tanto que eu casei com o Zélio'. Ziraldo um dia falou pra mim: "Eu tenho um irmão que eu vou apresentar para você e você vai casar com ele". Eu falei: "Eu não, não quero casar, imagina, casamento é uma coisa falida..." Casei. Estou casada há 54 anos com ele. Com essa turma toda foi feito $O$ Pasquim.

CLC: Quando você começou a desenhar?

C: Um pouco mais tarde, quando eu já estava com 18 ou 19 anos, eu comecei a fazer desenhos para o Cruzeiro, eu ilustrava e fazia matérias minhas. O editor era meu tio, então ele achava lindo.

'Zélio Alves Pinto é artista gráfico, integrou a equipe de O Pasquim e é um dos criadores do Salão Internacional de Humor de Piracicaba. 
Eu produzia coisas para crianças, roupas, desenhava vestidinhos. Ilustrei um livro, mas não era o que mais me movimentava. Eu publiquei de vez em quando alguns contos n'O Pasquim. E foi aí que eu comecei a pensar em criar alguma coisa minha. Eu comecei lá - com o pessoal do $O$ Pasquim - minha turma de cartunistas. Eu não fazia parte do pessoal de produção, mas a gente estava sempre junto e achei que eu gostaria de fazer isso, mas com eles eu só fiz texto. Então apareceu um suplemento no jornal dos esportes e me convidaram para participar. Eu fiz 10 suplementos de humor e eles publicaram os 10, eu não parei mais. Então quando eu voltei para São Paulo já estava com essa bagagem.

CLC: Como eram esses suplementos?

C: Eram suplementos de humor, mais "gags"2. Eu estava começando mesmo e eu escolhi fazer com animais, com pato, galinha, pintinhos. Funcionou porque eu tinha uma veia que não era bonitinha, era mais irônica. Quando eu vim para São Paulo, fui no Estadão, falei com Mino Carta e levei minha bagagem. Eu trouxe uma carta de recomendação do Odylo Costa Filho, que era um literato de muito prestígio na época. O Mino me recebeu e revelou uma coisa muito interessante: "Olha, não vou poder comprar suas coisas e vou te explicar o porquê. Não é porque não é bom, eu gostei, mas nós, para publicarmos as tiras de sucesso que eram Peanuts, Recruta Zero, somos obrigados a comprar um pacote com outras 500 mil tiras que ninguém gosta". Ele abriu uma gaveta falando: "Eu tenho tudo isso aqui, eu não posso comprar mais coisa porque eu teria que publicar isso primeiro. Não publico porque ninguém lê"3. Eu também fui falar com o Claudio Abrão, na Folha de S. Paulo, e ele falou: "Eu compro". Eu passei 20 anos lá e durante esse tempo, todos os dias, eu fazia uma tira para publicar. No começo eu fazia algumas e era muito primitivo. Não era como hoje que tem computador. Nessa época, comecei a fazer umas coisas mais familiares; então, tinha passarinhos, e eu fui me encaminhando para a política. Na Folha, eu criei um mundo que era das formigas, um formigueiro que era como se fosse um país que tinha um gambá que mandava na rainha, representando toda essa parte política. A parte feminista, feminina... eu fazia maternidade, fazia ocupação da mulher, aquela coisa do marido que é bonzinho, mas que espera que as coisas sejam feitas. Havia uma tirinha que eu fazia para o suplemento da Folha mesmo, uma mãe com uma filha adolescente. Isso foi ótimo porque eu tinha minha filha adolescente, a piada estava pronta em casa.

CLC: Como era ser uma mulher publicando n'O Pasquim?

C: Tinha uma pessoa que publicava uma das partes mais interessantes do semanário. Era a poeta Olga Savary, que era casada com o Jaguar. Na verdade, naquela época, a gente achava que "homem é assim mesmo". Sempre tive essa noção de que mulher é eletrônica e homem é mecânico. Era difícil, eu achava que não tinha muito jeito. Eles adoravam minha produção feminista, achavam bonitinho, eram bem paternalistas. O Henfil era um querido. Agora, o resto da turma d'O Pasquim... O Jaguar não, porque o Jaguar não estava nem aí para mulher. O Ziraldo, até hoje, é aquela coisa machista. Eu já trabalhei algumas vezes com ele, não é fácil. Eu nunca senti uma coisa de machismo no trabalho n'O Pasquim. A não ser quando eu fui despedida da Folha, que aí foi uma atitude machista, nojenta. O editor Matinas Suzuki me demitiu por machismo. Eu sempre, durante esses 20 anos, tinha o lugar da minha tira, era em primeiro. Matinas entrou e colocou a minha tira lá para baixo. Eu fui lá e falei: "Olha, eu queria voltar". O chefe dele mandou ele me botar em primeiro. Pronto, aí foi a minha morte. Ele falou que foi obrigado a fazer isso e eu disse: "Não, você fez a gentileza de me colocar no lugar onde eu sempre estive nos últimos 20 anos". Era um pouco de rivalidade.

CLC: Como começou sua produção mais voltada para as questões do trabalho doméstico e da maternidade? Você tinha algum tipo de relacionamento com leituras feministas, com mulheres de movimentos de mulheres?

C: Sim, tinha umas revistas norte-americanas, uma chamava-se Ms, que eu assinava, que era da Gloria Steinem. Eu também gostava dos textos da Betty Friedan, sempre tive esse olhar Anti-Elle, Anti-Vogue, sabe? Eu tinha esse olhar "não está dando certo". Eu era realmente muito atenta nesse período todo, mas eu acho que a gente não chegou no fim ainda. Eu acho que tem que acabar com o machismo. Quando eu estava lá atrás - antes de eu problematizar questões de mulheres e tudo -, eu achava que não tinha jeito, eu achava que homem não tem sensibilidade suficiente. Se você tira ele do pedestal ele desmorona, cai, vira areia. A gente também não quer isso. Eu achava que não tinha jeito lá atrás, mas depois a gente vai evoluindo. Tem jeito sim, demora mais uns três séculos.

\footnotetext{
${ }^{2}$ Sentido cômico desencadeado por um efeito surpresa.

${ }^{3}$ Até 1966 o mercado de quadrinhos brasileiro era completamente dominado por publicações estrangeiras. Por anos quadrinistas, jornalistas e cartunistas pressionaram o poder público pela Lei de Nacionalização que exigia, entre outras coisas, a publicação de quadrinhos e tirinhas nacionais.
} 
CLC: Como foi sua aproximação com os jornais feministas (Brasil Mulher, Nós Mulheres e Mulherio)? C: Quando a gente estava no pior da ditadura, eu estava batalhando na minha tribuninha. Eu, de certa maneira, estava falando naquelas tiras através das formigas, da galinha, do pato. Eu estava falando o que muita gente queria falar. Então, eu era muito visada pelos desagradáveis da época, mas eu estava com a confiança de quem estava querendo fazer alguma coisa. E elas me chamaram. Algumas me deram satisfação e outras me deram aborrecimentos. Uma delas, principalmente, que trabalhava no jornal do Paraná, o Brasil Mulher, levou os meus originais e falou: "A gente não tem grana para mandar fazer cópia de tudo isso, mas se você me emprestar os originais eu devolvo eles". Estou esperando até hoje, ela levou todos os meus originais. Isso foi muito ruim, fiquei muito aborrecida.

CLC: E o Nós Mulheres?

C: Alguém fez contato comigo e eu contribuía a cada número. Eu saía de tanto em tanto.

CLC: E o Mulherio?

C: Foi a mesma coisa. Todo mundo que me contatava e, se eu gostava de estar com o veículo, eu fazia. O trabalho das mulheres era de graça. E a Folha era quase de graça. Não era de graça, mas o pagamento era ridículo. Nos jornais em que eu trabalhava, eu recebia o exemplar. Lia tudo. Eu tinha três filhos pequenos e tinha meu pai que esteve doente por muitos anos. Então, tinha muita coisa além do sentar e fazer. E o sentar e fazer era muito mais trabalhoso porque era quase que artesanal.

CLC: Como eram construídas as ideias das tiras?

C: Isso é uma coisa que estava no ar. Não era "um fato aconteceu e eu me lembrei disso". Na minha tira da Bel, que tinha a filha adolescente, sim, eu mesma tinha uma filha adolescente. Me lembro uma vez que pedi para ela enxugar os pratos e ela se sentou na frente da televisão. Eu falei: "O que você tá fazendo?" E ela respondeu: "Eu tô enxugando os pratos". Tinha uma pilha de pratos na sala. Mas esse era outro aspecto. O aspecto mesmo da opressão que pairava era delicado, era amável, era até sutil. Por exemplo, me lembro de uma tirinha que fiz para o Mulherio, com a Bia Sabiá, que o pai falava: "Vamos fazer um piquenique, domingão, sol" (PINTO, 1976, p. 3). Não é uma coisa assim dolorosa, mas era o que existia, era assim, a vida era assim. Nesse sentido que, mesmo hoje, se você olhar com atenção, faz uma tirinha dessas por dia. Não sei se você percebeu que eu gosto muito da palavra, a palavra é uma coisa muito rica. Há jogos que você pode fazer e eu tenho uns vinte livros que usam esse recurso da palavra com suas modificações. Eu gosto de fazer também bichinhos, mas nunca bonitinho, não gosto de bonitinho, eu gosto de uma coisa com humor. Eu acho humor a salvação da lavoura.

CLC: Para você qual o papel do humor?

C: Eu acho o humor didático, sem ser didático. O humor mostra não como as coisas devem ser, mas como as coisas não devem ser, sutilmente. Eu acho o humor uma dádiva. O humor é sempre contra. É sempre contra alguma coisa. Contanto que não seja contra o outro, rir da desgraça alheia. Em alemão tem até tem uma palavra para isso, o prazer de ver o outro sofrer: "schadenfreude". Isso eu acho horrivel, mas você mostrar como aquela atitude, aquela coisa que não é harmoniosa, que ela teria que ser diferente. Isso eu acho didático, sem ser didático.

CLC: Como foi construída tua relação com as tirinhas?

C: Eu sou apaixonada por tirinhas, por quadrinhos, desde pequena. Meu pai queria que eu falasse inglês, ele já tinha me arranjado uma professora e eu a detestava. Eu era muito pequena, achava um saco ficar lá o dia inteiro tendo aula. Ele importava livros norte-americanos que eram coloridos, tinha até dourado, tinha ilustrações com dourado e quadrinhos. Eu tinha uma biblioteca de quadrinhos encadernados da Disney. Qualquer personagem antigo eu tinha e eu lia em inglês. Eu sempre fui apaixonada. Disney era uma maravilha, antes, sabe? Quando era uma coisa antiga, as histórias eram sensacionais, você aprendia histórias do Egito, sobre os maias, tudo muito historicamente estudado e muito engraçado. Depois, virou produção em massa, mas quando eu era pequena eram muito bons. Eu também tinha quadrinhos franceses e uma revista chamada La Semaine de Suzette. Eu vivia de quadrinhos.

CLC: Você se recorda de consumir quadrinhos produzidos por mulheres?

C: Não, apenas muito tarde, muito depois. Eram muito poucas. Tinha uma exceção, Luluzinha. A Luluzinha era de autoria de uma mulher e aqui foi traduzido por uma mulher. Quem traduzia era uma das minhas primas e ela traduzia muito bem. Luluzinha era a única e não tinha outras que eu conhecesse. Tinha pouca mulher fazendo tirinhas, quadrinhos, mas tem muitos personagens femininos, muitos. 
CLC: No período que você publicava nos jornais feministas, havia outras companheiras cartunistas? C: Pouquíssimas mulheres. No começo quase nenhuma, depois $\mathrm{Crau}^{4}$ começou a fazer e tinha uma que se chamava Cahú ${ }^{5}$ que era muito boa. Depois, tinham algumas, mas eu já estava produzindo fazia tempo. Tinha muita ilustradora boa, chargista, isso tinha.

CLC: Você vem acompanhando a produção de mulheres hoje?

C: Sim, acho engraçado porque tenho impressão que agora tem muito mais mulheres fazendo do que homem. Eu tenho observado que o aporte de quadrinhos de mulher está sendo muito maior do que de homem, tem muito menos rapazes novinhos querendo investir nos quadrinhos do que mulheres. Mulheres têm se demonstrado mais apaixonadas, é uma paixão mesmo.

CLC: Você acha que as mulheres produzem quadrinhos/tirinhas de uma maneira diferente?

C: Acho, eu acho que o olhar é totalmente outro. O olhar é totalmente outro mesmo. Obviamente eu não me lembro de tudo o que eu fiz, não dá para lembrar, mas quando eu vejo o meu trajeto individual, familiar, de costumes e meu movimento para a política, eu acho que o meu olhar era diferente do que o do pessoal do O Pasquim. Não tinha quase nenhum ponto de encontro. Durante a ditadura, cada um fazendo a sua trincheira, também era diferente, a maneira de você dizer as coisas. Eu acho que, sim, eu acho que a mulher tem uma maneira diferente de produzir. De qualquer maneira, mesmo dividindo o campo de trabalho, são olhares diferentes. Acho mesmo que o homem é mecânico e a mulher é eletrônica. O homem tem um olhar menos completo, acho que a mulher tem um olhar mais completo.

\section{Referências}

PINTO, Cecília Alves. [CIÇA]. Mulherio, Brasil, Edição 2, set-out 1976.

Cintia Lima Crescêncio (cintia.crescencio@ufms.br) é professora do curso de História da Universidade Federal do Mato Grosso do Sul (UFMS), Campus de Três Lagoas/MS - Brasil. Possui mestrado e doutorado pelo Programa de Pós-Graduação em História Cultural pela Universidade Federal de Santa Catarina (UFSC). Coordena o Grupo de Pesquisa História, Mulheres e Feminismo (HIMUFE) e realiza pesquisas no campo dos estudos de gênero, estudos feministas e humor.

\section{COMO CITAR ESSE ARTIGO DE ACORDO COM AS NORMAS DA REVISTA}

CRESCÊNCIO, Cintia Lima. "'O humor mostra... como as coisas não devem ser': uma entrevista com Ciça". Revista Estudos Feministas, Florianópolis, v. 27, n. 3, e56148, 2019.

\section{CONTRIBUIÇÃO DE AUTORIA}

Não se aplica

\section{FINANCIAMENTO}

Não se aplica

\section{CONSENTIMENTO DE USO DE IMAGEM}

Não se aplica

\section{APROVAÇÃO DE COMITÊ DE ÉTICA EM PESQUISA}

Não se aplica

\footnotetext{
${ }^{4}$ Maria Claudia França Nogueira, mais conhecida como Crau da llha, ou apenas Crau, contribuiu com o jornal O Bicho, na década de 1970. Em 2004 publicou a revista As Periquitas, cuja chamada é Meninas com Humor e Opinião, publicação que reuniu 40 artistas, cartunistas e quadrinistas mulheres.

${ }^{5}$ Maria da Conceição de Souza Cahú, mais conhecida como Cahú, contribuiu com o jornal Gazeta Mercantil, publicando retratos a bico de pena. Também produzia charges, tiras e quadrinhos. Era figura assídua nas páginas do jornal feminista Brasil Mulher, na década de 1970, onde publicava quadrinhos que versavam sobre a mulher operária.
} 


\section{CONFLITO DE INTERESSES}

Não se aplica

LICENÇA DE USO

Este artigo está licenciado sob a Licença Creative Commons CC-BY International. Com essa licença você pode compartilhar, adaptar, criar para qualquer fim, desde que atribua a autoria da obra.

\section{HISTÓRICO}

Recebido em 02/04/2018

Aprovado em $07 / 11 / 2018$ 